\title{
A Study to Assess the Factors Affecting Adherence to Exercise in the Indian Population
}

\author{
Shruti Shettigar $^{1}$, Kiran Shivaraj ${ }^{2}$, Sneha Shettigar ${ }^{3}$ \\ 1. Internal Medicine, Rajarshee Chhatrapati Shahu Maharaj Government Medical College and CPR Hospital, Kolhapur, \\ IND 2. Internal Medicine, Brookdale University Hospital and Medical Center, Brooklyn, USA 3. Preventive Medicine, \\ SMBT Institute of Medical Sciences \& Research Centre, Igatpuri, IND
}

Corresponding author: Shruti Shettigar, shrutiks1393@gmail.com

\begin{abstract}
\section{Introduction}

As proven by many previous studies, physical inactivity is associated with many diseases, including heart conditions and cancer. The elimination of physical inactivity helps increase life expectancy and reduce morbidity. Nonadherence to exercise is a common problem faced by many people. The goal of this study was to determine the percentage of people in the Indian population who regularly exercise. We also assessed factors for nonadherence, motivating factors, and the intensity of exercise usually performed and explored any association between adherence to exercise and demographic factors.
\end{abstract}

\section{Materials and methods}

We conducted an anonymous questionnaire-based, cross-sectional study in an adult Indian population (participants were older than 18 years) from rural and urban areas having no contraindication to at least some form of voluntary exercise. Data were collected via email by sending a questionnaire, and an appropriate statistical methodology was used to derive the results.

\section{Results}

This study included 220 individuals older than 18 years, and most participants were aged 25 to 30 years (35.5\%). Most participants (67.3\%) were women, and $32.7 \%$ were men. Forty-one percent of the total population reported suffering from some medical condition. Nearly half $(51.8 \%)$ of the subjects were involved in physical activity, and $48.2 \%$ were not involved in physical activity. The most common reason for not exercising was a lack of time followed by a lack of motivation. Maintenance of good health was the main reported benefit of physical exercise, with self-motivation being the main motivator. Low-intensity exercise was the preferred form of exercise for most of the participants; high-intensity exercise was preferred by younger participants, though less commonly than low-intensity exercise. Older participants (i.e., those aged $>40$ years) preferred moderate-intensity exercise. Only half the study population were educated regarding physical activity by a healthcare professional. We found no statistically significant association between the

Received 10/16/2019

Review began 10/22/2019 Review ended 11/01/2019 Published 11/03/2019

\section{() Copyright 2019}

Shettigar et al. This is an open access article distributed under the terms of the Creative Commons Attribution License CC-BY 3.0., which permits unrestricted use, distribution, and reproduction in any medium, provided the original author and source are credited. presence of a medical condition, body mass index (BMI), or healthcare education and adherence to exercise.

\section{Conclusion}

The inclusion of exercise in a daily routine is one of the more important lifestyle changes advised for all ailments and for improvements in patient quality of life. Nearly half the Indian population does not exercise daily. Because we found no statistical significance between demographic factors, health conditions, BMI, or general healthcare education, an individualized education and exercise plan may help improve exercise adherence.

Categories: Preventive Medicine, Public Health, Epidemiology/Public Health

Keywords: exercise, physical activity, lifestyle, indian population

\section{Introduction}

The American College of Sports Medicine recommends that adults should engage in at least 30 minutes of moderate-intensity exercise five times per week, vigorous-intensity exercise for at least 20 minutes per day, three days per week, or a combination of both moderate and vigorous activity [1]. Given the growing, aging population and unhealthy lifestyle choices, the incidence of chronic diseases has increased [2-3]. The number of patients with diabetes has quadrupled, especially in low- and middle-income countries [2]. The prevalence of hypertension in 2010 was $28.5 \%$ to $31.5 \%$, and the age-standardized increase in prevalence was greater in low- to middle-income countries as compared to high-income countries (where the prevalence was reduced) [3]. Exercise or physical activity is beneficial in reducing cardiovascular risks in patients with chronic diseases such as diabetes and hypertension [4-5]. One study reported that the elimination of physical inactivity would increase the life expectancy of the world's population by 0.68 years 


\section{Cureus}

(range, $0.41-0.95$ years) [6].

The same study also estimated that worldwide, physical inactivity causes $6 \%$ of the burden of disease from coronary heart disease, $7 \%$ of the type 2 diabetes burden, $10 \%$ of the breast cancer burden, and $10 \%$ of the colon cancer burden. Inactivity causes $9 \%$ of premature mortality or more than 5.3 million of the 57 million deaths that occurred worldwide in 2008 [6]. If inactivity were not eliminated but decreased instead by $10 \%$ or $25 \%$, more than 533,000 deaths and more than 1.3 million deaths, respectively, could be averted every year $[6]$.

Typically, 50\% of the individuals who begin an exercise program stop within the first six months [7]. The challenge usually faced is having the right motivation to inculcate exercise into the daily routine, finding time for it in a busy schedule, and sticking to the regimen for a long duration. The goal of this study was to determine the percentage of people in India who regularly exercise. We also analyzed factors for nonadherence to exercise regimens, motivating factors, and the intensity of exercises performed, and we explored the associations between adherence to exercise and demographic data.

\section{Materials And Methods}

We conducted an anonymous survey of adults (those aged 18 or older) in an Indian population from both urban and rural areas. The purpose of the study was explained to the participants, and a questionnaire was designed and sent to the participants via email. We included patients older than 18 years who had no contraindication to at least some form of voluntary exercise. As it was a voluntary study, we assumed that all subjects who completed and returned the questionnaire implied consent to include their responses in the study results. Those who were not able to engage in any form of exercise due to disability or medical reasons were excluded from the study. The data obtained after compiling the survey answers were analyzed for various factors affecting adherence to exercise, including demographic factors, medical conditions, and access to health care.

\section{Results}

A total of 220 respondents $(67.3 \%$ men $(n=148)$, 32.7\% women $(n=72))$ were included in the study. The largest age group was of respondents aged 25 to 30 years (35.5\%; Table 1 ).

\begin{tabular}{|c|c|c|}
\hline Age (Years) & Frequency (n) & Percent \\
\hline $18-25$ & 63 & $28.6 \%$ \\
\hline $25-30$ & 78 & $35.5 \%$ \\
\hline $30-40$ & 21 & $9.5 \%$ \\
\hline$>40$ & 58 & $26.4 \%$ \\
\hline Total & 220 & $100 \%$ \\
\hline
\end{tabular}

TABLE 1: Distribution of sample according to age

Most of the respondents ( $\mathrm{n}=204,92.7 \%)$ resided in an urban area, and $16(7.3 \%)$ resided in rural areas. Nearly half of all respondents (50.5\%) had graduated from college, and $40.5 \%$ completed postgraduate education. Forty-one respondents (18.6\%) reported suffering from some form of medical condition.

Slightly more than half of the respondents ( $\mathrm{n}=114,51.8 \%)$ reported involvement in some physical activity regularly. The remaining 106 participants (48.2\%) were not exercising regularly (Table 2). 


\section{Cureus}

\begin{tabular}{|l|l|l|}
\hline Assessment according to whether doing exercise on a regular basis & Frequency (n) & Percent \\
\hline No & 106 & $48.2 \%$ \\
\hline Yes & 114 & $51.8 \%$ \\
\hline Total & 220 & $100 \%$ \\
\hline
\end{tabular}

\section{TABLE 2: Exercise frequency}

Most respondents ( $\mathrm{n}=127,57.7 \%)$ reported engaging in some physical exercise in the last week. Only 20 (9.1

$\%$ ) respondents reported not remembering the last time they exercised (Table 3).

\begin{tabular}{|c|c|c|}
\hline Assessment according to when last time did exercise & Frequency (n) & Percent \\
\hline Do not remember & 20 & $9.1 \%$ \\
\hline Last week & 127 & $57.7 \%$ \\
\hline$>1$ week & 18 & $8.2 \%$ \\
\hline$>1$ month & 39 & $17.7 \%$ \\
\hline$>1$ year & 16 & $7.3 \%$ \\
\hline Total & 220 & $100 \%$ \\
\hline
\end{tabular}

TABLE 3: Time since last exercise

The most common reason given for not exercising was lack of time (Figure 1), reported by $56.4 \%$ of the population. Lack of motivation was the second most common reason, as seen in $23.6 \%$ of the population.

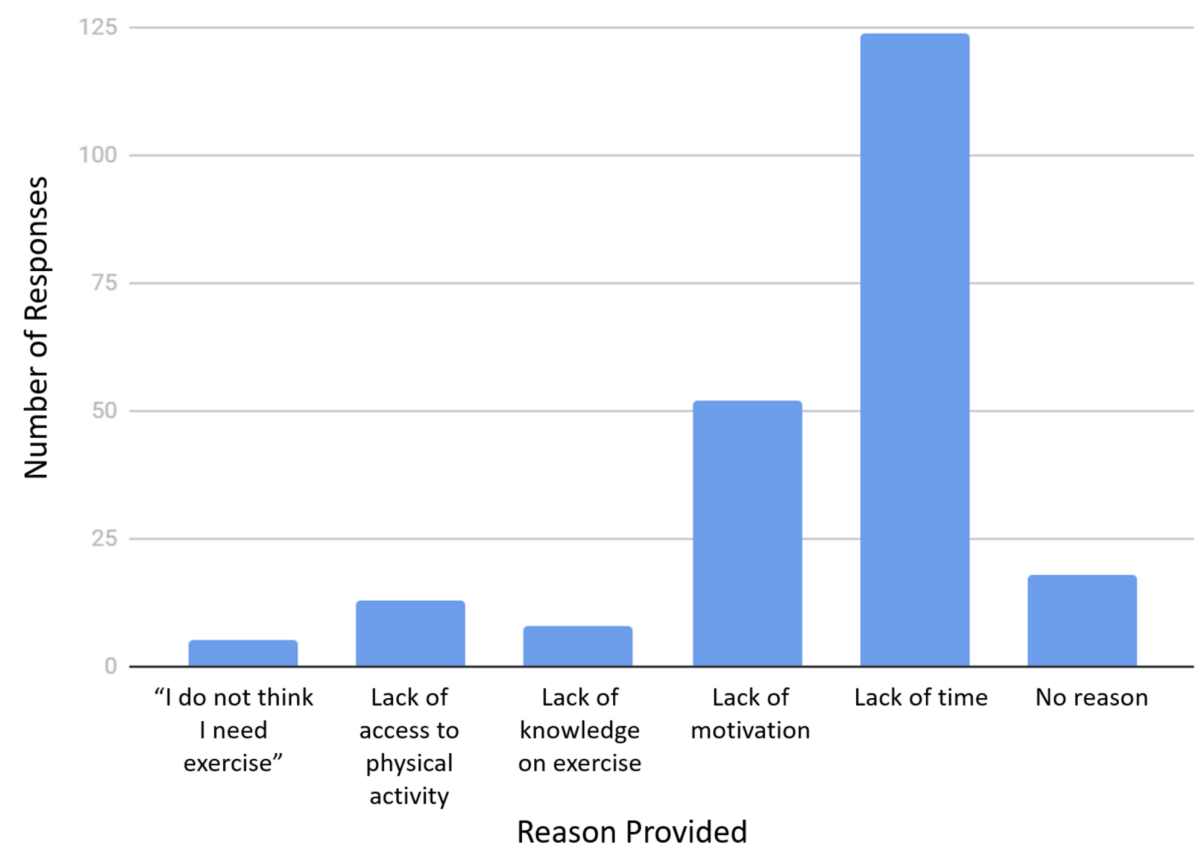

FIGURE 1: Assessment according to the main reason for not exercising

The most common reason for exercising was to maintain good health, according to $69.1 \%$ of the study 


\section{Cureus}

population; weight loss was the given reason by only $13.2 \%$ of the study subjects.

Among 220 respondents, 101 (45.9\%) respondents did not receive any advice from any healthcare professional. Ninety-two (41.8\%) respondents reported receiving advice from a healthcare professional, and the remaining 27 (12.3\%) respondents were not sure whether they received any advice from any healthcare professional (Table 4).

\begin{tabular}{|c|c|c|}
\hline $\begin{array}{l}\text { Assessment according to whether received any advice from a healthcare professional regarding } \\
\text { physical activity }\end{array}$ & $\begin{array}{l}\text { Frequency } \\
\text { (n) }\end{array}$ & Percent \\
\hline Maybe & 27 & $12.3 \%$ \\
\hline No & 101 & $45.9 \%$ \\
\hline Yes & 92 & $41.8 \%$ \\
\hline
\end{tabular}

\section{TABLE 4: Counseling from a healthcare professional regarding physical activity}

Of those surveyed, 119 (54.1\%) said self-motivation was their motivation for exercise. Fifty-four (24.5\%) people said a health condition was the main motivation for exercising (Table 5).

\begin{tabular}{|c|c|c|}
\hline Motivation for exercise & Frequency (n) & Percent \\
\hline Friend, family, spouse, personal trainer & 41 & $18.6 \%$ \\
\hline Health condition & 54 & $24.5 \%$ \\
\hline Self-motivation & 119 & $54.1 \%$ \\
\hline Social media & 6 & $2.7 \%$ \\
\hline Total & 220 & $100 \%$ \\
\hline
\end{tabular}

\section{TABLE 5: Exercise motivation}

Many respondents ( $\mathrm{n}=97,44.1 \%$ ) preferred low-intensity exercises like slow cycling, slow walking, or yoga, and 89 (40.5\%) respondents said they engaged in moderate-intensity exercise like brisk walking, jogging, or dancing. Only 34 (15.5\%) respondents said they did high-intensity exercise like running, aerobic dancing, or swimming (Table 6).

\begin{tabular}{|c|c|c|}
\hline Exercise & Frequency (n) & Percent \\
\hline High-intensity (running, aerobic dancing, swimming) & 34 & $15.5 \%$ \\
\hline Low-intensity (slow cycling, slow walking, yoga) & 97 & $44.1 \%$ \\
\hline Moderate-intensity (brisk walking, jogging, dancing) & 89 & $40.5 \%$ \\
\hline Total & 220 & $100 \%$ \\
\hline
\end{tabular}

\section{TABLE 6: Exercise by intensity/type}

We conducted a chi-square test (Table 7) to determine whether adherence to exercise is associated with selected demographic variables such as age, gender, and education. The calculated chi-square value of age, gender, and education are less than their respective chi-square table value at 0.05 levels. Thus, there is no statistically significant difference between groups of demographic variables of age, gender, and education with respect to adherence to exercise. 


\section{Cureus}

\begin{tabular}{|c|c|c|c|c|c|c|c|c|}
\hline \multicolumn{2}{|c|}{ Demographic variable } & \multicolumn{2}{|c|}{$\begin{array}{l}\text { Adherence to } \\
\text { exercise }\end{array}$} & \multirow{2}{*}{ df } & \multirow{2}{*}{$\begin{array}{l}\text { Calc. } X^{2} \\
\text { value }\end{array}$} & \multirow{2}{*}{$\begin{array}{l}\text { Table } \mathbf{X}^{2} \\
\text { value }\end{array}$} & \multirow{2}{*}{$\begin{array}{l}p- \\
\text { value }\end{array}$} & \multirow{2}{*}{$\begin{array}{l}\text { Whether significant at } 0.05 \\
\text { level }\end{array}$} \\
\hline & & No & Yes & & & & & \\
\hline \multirow{4}{*}{$\begin{array}{l}\text { Age } \\
\text { (years) }\end{array}$} & $18-25$ & 28 & 35 & \multirow{4}{*}{3} & \multirow{4}{*}{7.38} & \multirow{4}{*}{7.82} & \multirow{4}{*}{0.061} & \multirow{4}{*}{ No } \\
\hline & $25-30$ & 44 & 34 & & & & & \\
\hline & $30-40$ & 13 & 8 & & & & & \\
\hline & $>40$ & 21 & 37 & & & & & \\
\hline \multirow{2}{*}{ Gender } & Male & 36 & 36 & \multirow{2}{*}{1} & \multirow{2}{*}{0.14} & \multirow{2}{*}{3.84} & \multirow{2}{*}{0.707} & \multirow{2}{*}{ No } \\
\hline & Female & 70 & 78 & & & & & \\
\hline \multirow{3}{*}{ Education } & $\begin{array}{l}12 \text { th year and } \\
\text { below }\end{array}$ & 10 & 10 & \multirow{3}{*}{2} & \multirow{3}{*}{3.69} & \multirow{3}{*}{5.99} & \multirow{3}{*}{0.158} & \multirow{3}{*}{ No } \\
\hline & Graduate & 60 & 51 & & & & & \\
\hline & Postgraduate & 36 & 53 & & & & & \\
\hline
\end{tabular}

TABLE 7: Association of demographic with adherence to exercise

Abbreviations: $\mathrm{df}$, degree of freedom; $\mathrm{X}^{2}$, chi-square statistic

We also used the chi-squared test to determine whether adherence to exercise is associated with previous medical conditions (Table 8). The calculated chi-square value is less than the respective chi-square table value at 0.05 levels. Thus, we found no statistically significant difference between medical conditions with respect to adherence to exercise.

\begin{tabular}{|c|c|c|c|c|c|c|c|c|}
\hline \multirow{2}{*}{ Association } & & \multicolumn{2}{|c|}{$\begin{array}{l}\text { Adherence to } \\
\text { exercise }\end{array}$} & \multirow{2}{*}{ df } & \multirow{2}{*}{$\begin{array}{l}\text { Calc. } X^{2} \\
\text { value }\end{array}$} & \multirow{2}{*}{$\begin{array}{l}\text { Table } X^{2} \\
\text { value }\end{array}$} & \multirow{2}{*}{$\begin{array}{l}\text { p- } \\
\text { value }\end{array}$} & \multirow{2}{*}{$\begin{array}{l}\text { Whether significant at } 0.05 \\
\text { level }\end{array}$} \\
\hline & & No & Yes & & & & & \\
\hline \multirow{2}{*}{$\begin{array}{l}\text { Any medical } \\
\text { condition }\end{array}$} & No & 91 & 88 & \multirow{2}{*}{1} & \multirow{2}{*}{2.71} & \multirow{2}{*}{3.84} & \multirow{2}{*}{0.099} & \multirow{2}{*}{ No } \\
\hline & Yes & 15 & 26 & & & & & \\
\hline
\end{tabular}

\section{TABLE 8: Association of medical condition with adherence to exercise.}

Abbreviations: $\mathrm{df}$, degree of freedom; $\mathrm{X}^{2}$, chi-square statistic.

Table 9 shows the association of age with different forms of exercise, such as low-, moderate-, and highintensity exercise. The calculated chi-square value of 18.65 is more than the chi-square table value of 12.59 at 0.05 levels. Thus, we noted a statistically significant difference between age and forms of exercise. Younger age group respondents (e.g., 18 to 25 -year-olds and 25 to 30-year-olds) engaged in higher intensity exercise compared to older respondents. Thus, statistically, age is associated with different forms of exercise. 


\section{Cureus}

\begin{tabular}{|c|c|c|c|c|c|c|c|c|c|}
\hline \multirow{2}{*}{\multicolumn{2}{|c|}{$\begin{array}{l}\text { Association of age with form } \\
\text { of exercise }\end{array}$}} & \multicolumn{3}{|c|}{ Form of exercise } & \multirow{2}{*}{ df } & \multirow{2}{*}{$\begin{array}{l}\text { Calc. } X^{2} \\
\text { value }\end{array}$} & \multirow{2}{*}{$\begin{array}{l}\text { Table } X^{2} \\
\text { value }\end{array}$} & \multirow{2}{*}{$\begin{array}{l}\mathrm{p}- \\
\text { value }\end{array}$} & \multirow{2}{*}{$\begin{array}{l}\text { Whether significant at } \\
0.05 \text { level }\end{array}$} \\
\hline & & $\begin{array}{l}\text { Low } \\
\text { Intensity }\end{array}$ & $\begin{array}{l}\text { Moderate } \\
\text { Intensity }\end{array}$ & $\begin{array}{l}\text { High } \\
\text { Intensity }\end{array}$ & & & & & \\
\hline \multirow{4}{*}{ Age (years) } & $18-25$ & 35 & 18 & 10 & \multirow{4}{*}{6} & \multirow{4}{*}{18.65} & \multirow{4}{*}{12.59} & \multirow{4}{*}{0.0048} & \multirow{4}{*}{ Yes } \\
\hline & $25-30$ & 26 & 36 & 16 & & & & & \\
\hline & $30-40$ & 9 & 8 & 4 & & & & & \\
\hline & $>40$ & 19 & 35 & 4 & & & & & \\
\hline
\end{tabular}

\section{TABLE 9: Association of age with form of exercise}

Abbreviations: df, degree of freedom; $\mathrm{X}^{2}$, chi-square statistic

Table 10 shows the association of BMI with adherence to exercise. As BMI data are in parametric format, we used the unpaired ' $t$ ' test to find the difference in mean BMI with respect to adherence to exercise. The calculated ' $t$ ' test value of 0.73 is less than the ' $t$ ' test table value of 1.96 at 0.05 levels with a degree of freedom of 218 . Thus, we found no statistically significant difference in mean BMI with respect to adherence to exercise.

\begin{tabular}{|c|c|c|c|c|c|c|c|c|c|c|}
\hline \multicolumn{2}{|c|}{$\begin{array}{l}\text { Association of BMI with adherence } \\
\text { to exercise }\end{array}$} & $\mathbf{n}$ & $\begin{array}{l}\text { Mean } \\
\text { BMI }\end{array}$ & MD & SEMD & df & $\begin{array}{l}\text { Calc. 't' } \\
\text { value }\end{array}$ & $\begin{array}{l}\text { Table 't' } \\
\text { value }\end{array}$ & $\begin{array}{l}\text { p- } \\
\text { value }\end{array}$ & $\begin{array}{l}\text { Whether significant at } \\
0.05 \text { levels }\end{array}$ \\
\hline Whether exercising regularly & $\begin{array}{l}\text { Yes } \\
\text { No }\end{array}$ & $\begin{array}{r}114 \\
106\end{array}$ & $\begin{array}{l}24.09 \\
24.55\end{array}$ & 0.46 & 0.61 & 218 & 0.73 & 1.96 & 0.468 & No \\
\hline
\end{tabular}

\section{TABLE 10: BMI and adherence to exercise}

Abbreviations: BMI, body mass index; df, degree of freedom; MD, mean of the difference score; SEMD, standard error of mean of the difference score

Table 11 shows the association of healthcare advice with adherence to exercise. Twenty-seven people said they were unsure if they received healthcare advice and were excluded from this analysis. The calculated chisquare value of 1.631 is more than the chi-square table value of 3.841 at 0.05 levels. Therefore, advice from a healthcare provider was not statistically significant.

\begin{tabular}{|c|c|c|c|c|c|c|c|c|}
\hline \multirow{2}{*}{$\begin{array}{l}\text { Association of healthcare advice with } \\
\text { adherence to exercise }\end{array}$} & & \multicolumn{2}{|c|}{$\begin{array}{l}\text { Adherence to } \\
\text { exercise }\end{array}$} & \multirow{2}{*}{ Total } & \multirow{2}{*}{$\begin{array}{l}\text { Calc. } X^{2} \\
\text { value }\end{array}$} & \multirow{2}{*}{$\begin{array}{l}\text { Table } X^{2} \\
\text { value }\end{array}$} & \multirow{2}{*}{$\begin{array}{l}\text { p- } \\
\text { value }\end{array}$} & \multirow{2}{*}{$\begin{array}{l}\text { Whether significant at } \\
0.05 \text { level }\end{array}$} \\
\hline & & Yes & No & & & & & \\
\hline \multirow{2}{*}{ Healthcare advice received } & Yes & 54 & 38 & 92 & \multirow{2}{*}{1.631} & \multirow{2}{*}{3.841} & \multirow{2}{*}{0.2013} & \multirow{2}{*}{ No } \\
\hline & No & 50 & 51 & 101 & & & & \\
\hline
\end{tabular}

\section{TABLE 11: Healthcare advice and adherence to exercise}

Abbreviations: $\mathbf{X}^{2}$, chi-square

Age, gender, or education were not factors affecting whether a person exercises or not, and, therefore, a separate intervention targeting a specific group based on age, gender, or educational status would not be effective. The presence of a pre-existing medical condition did not influence a person towards better compliance with an exercise regime; this might be due to the low number of respondents who received education regarding the benefits of exercise. There was a significant association between age and the intensity of exercise, with more subjects in the younger population engaging in high-intensity exercise 


\section{Discussion}

The age distribution of the study population showed a relatively younger population, with $64 \%$ of the subjects between the ages of 18 and 30 years with $92.7 \%$ of them residing in an urban area - these are mainly due to the design of the study, which requires the accessibility to the Internet either on the computer or on the phone. Many of the patients were educated with either a graduate or postgraduate degree; this again can be attributable to the study population being predominantly urban where access to education is more readily available than in rural areas. About half the population had a routine habit of exercising, which closely matched with the reported data that $57.7 \%$ did some exercise in the last week. Even among the patients who did not exercise regularly, a very small proportion of about $9.1 \%$ reported they did not remember the last time they exercised, suggesting a large number of the people in the study population participated in some physical activity. Our results align with Lawton et al.'s report [8] on a south Asian population who migrated to the United Kingdom in that a lack of time was the most commonly stated reason for not exercising. A significant proportion of respondents (23.6\%) also mentioned a lack of motivation as the reason for the lack of physical activity, which, according to previous studies, can be modified by health education [9], yet only $41 \%$ of our respondents recalled a health professional advising them on levels of physical activity. Surprisingly, most of the population preferred to do low- to moderate-intensity exercise, which, as per previous studies, has shown to have better compliance when compared to high-intensity exercise [9].

Despite reports that high-intensity exercise is associated with low adherence [10], a small study done by Jonathan et al. on eight healthy volunteers showed high-intensity interval running to be more enjoyable based on the physical activity enjoyment scale versus moderate-intensity continuous running [11], which might translate to better adherence to exercise in people who can participate in such an activity. There was no significant association between BMI and adherence to exercise, which is not preferable as people with higher BMI are expected to exercise regularly-which again can be attributable to lack of health education. A structured program for providing education regarding physical activity with individual-level tailoring and with population-wide initiatives may inspire better rates of participation in exercise.

Our findings indicate there is no statistically significant difference between engaging in exercise and receiving healthcare advice, which did not align with our expectations. The discrepancy may be due to the study design's use of a questionnaire-based survey, which only assessed whether the participant received any form of advice from a healthcare professional. The survey did not involve questions regarding the level of aggressiveness or efficacy of the counseling received, whether any personalized exercise regimen was advised, or any follow-up measures were emphasized.

\section{Conclusions}

The inclusion of exercise into the daily routine is an important lifestyle change for many patients. This anonymous questionnaire-based, cross-sectional study in an adult Indian population to assess the percentage of people in the Indian population who regularly exercise and factors for nonadherence, motivating factors, and the intensity of exercise usually performed and any association between adherence to exercise and demographic factors. Nearly half the Indian population does not exercise daily. Because we found no statistical significance between demographic factors, health conditions, BMI, or general healthcare education, we suggest measures be taken to inspire better rates of participation in exercise, perhaps via a structured program for providing tailored education regarding physical activity with individual-level tailoring and with population-wide initiatives.

\section{Additional Information \\ Disclosures}

Human subjects: Consent was obtained by all participants in this study. Animal subjects: All authors have confirmed that this study did not involve animal subjects or tissue. Conflicts of interest: In compliance with the ICMJE uniform disclosure form, all authors declare the following: Payment/services info: All authors have declared that no financial support was received from any organization for the submitted work. Financial relationships: All authors have declared that they have no financial relationships at present or within the previous three years with any organizations that might have an interest in the submitted work. Other relationships: All authors have declared that there are no other relationships or activities that could appear to have influenced the submitted work.

\section{References}

1. Haskell WL, Lee IM, Pate RR, et al.: Physical activity and public health. Updated recommendation for adults from the American College of Sports Medicine and the American Heart Association. Circulation. 2007, 116:1081-1093. 10.1161/CIRCULATIONAHA.107.185649

2. NCD Risk Factor Collaboration (NCD-RisC): Worldwide trends in diabetes since 1980: a pooled analysis of 751 population-based studies with 4.4 million participants. Lancet. 2016, 387:1513-1530. 10.1016/S0140- 


\section{Cureus}

6736(16)00618-8

3. Mills KT, Bundy JD, Kelly TN, et al.: Global disparities of hypertension prevalence and control: a systematic analysis of population-based studies from 90 countries. Circulation. 2016, 134:441-450.

10.1161/CIRCULATIONAHA.115.018912

4. Chen L, Pei JH, Kuang J, Chen HM, Chen Z, Li ZW, Yang HZ: Effect of lifestyle intervention in patients with type 2 diabetes: a meta-analysis. Metabolism. 2015, 64:338-347. 10.1016/j.metabol.2014.10.018

5. Whelton SP, Chin A, Xin X, He J: Effect of aerobic exercise on blood pressure: a meta-analysis of randomized, controlled trials. Ann Intern Med. 2002, 136:493-503. 10.7326/0003-4819-136-7-20020402000006

6. Lee IM, Shiroma EJ, Lobelo F, Puska P, Blair SN, Katzmarzyk PT, Lancet Physical Activity Series Working Group: Effect of physical inactivity on major noncommunicable diseases worldwide: an analysis of burden of disease and life expectancy. Lancet. 2012, 380:219-229. 10.1016/S0140-6736(12)61031-9

7. Dishman RK: Compliance/adherence in health-related exercise. Health Psychol. 1982, 1:237-267. 10.1037/0278-6133.1.3.237

8. Lawton J, Ahmad N, Hanna L, Douglas M, Hallowell N: 'I can't do any serious exercise': barriers to physical activity amongst people of Pakistani and Indian origin with type 2 diabetes. Health Educ Res. 2006, 21:4354. 10.1093/her/cyh042

9. McAuley E, Courneya KS, Rudolph DL, Lox CL: Enhancing exercise adherence in middle-aged males and females. Prev Med. 1994, 23:498-506. 10.1006/pmed.1994.1068

10. Perri MG, Anton SD, Durning PE, et al.: Adherence to exercise prescriptions: effects of prescribing moderate versus higher levels of intensity and frequency. Health Psychol. 2002, 21:452-458. 10.1037/02786133.21.5.452

11. Bartlett JD, Close GL, MacLaren DP, Gregson W, Drust B, Morton JP: High-intensity interval running is perceived to be more enjoyable than moderate-intensity continuous exercise: implications for exercise adherence. J Sports Sci. 2011, 29:547-553. 10.1080/02640414.2010.545427 